\title{
A sunshine act for Europe
}

\author{
Fiona Godlee editor, BMJ
}

As the days grow shorter in this northern outpost of Europe, we can dream about sunshine, real and metaphorical. Barack Obama's Sunshine Act comes into force in 2013, requiring drug companies to declare all payments and hospitality they give to doctors. As Andrew Jack explains, the aggressive marketing of drugs in the United States is now being met with an equally aggressive response from government, fuelled by exposés, law suits, and public pressure (doi:10.1136/bmj.d6459).

Jennifer Neuman and colleagues give the bandwagon another shove (doi:10.1136/bmj.d5621). Their review of clinical guidelines in the US and Canada finds that half the panel members had conflicts of interest. These were substantially more common on non-government sponsored guidelines and were especially prevalent on guidelines produced by specialty societies, a fact not lost on Edwin Gale in his linked editorial (doi:10.1136/bmj.d5728).

Other countries already have or are considering their own sunshine acts. Denmark has required companies to declare their payments to doctors since 2008, and France is currently drafting legislation. As far as I am aware, nothing of this sort is on the cards in the UK. Instead UK doctors are expected to abide by the General Medical Council's good medical practice guidelines: "You must act in your patients' best interests when making referrals and when providing or arranging treatment or care. You must not ask for or accept any inducement, gift, or hospitality which may affect or be seen to affect the way you prescribe for, treat, or refer patients."

But thinking that individual doctors can avoid links with industry is unrealistic, says Gale. "Money from drug companies and the influence it buys [are] integral to the way medicine is done, and the carefully nurtured belief that clinicians can navigate all this amid the odour of sanctity and scientific objectivity is mere illusion." What is needed, he says, is a change of culture "in which serving two masters becomes as socially unacceptable as smoking a cigarette."

Gale doesn't say how to achieve this change of culture, but his analogy with smoking might be helpful. Doctors led the way in the early anti-smoking campaigns, with posters saying "Think first-most doctors don't smoke." Now it's doctors who must clean up their act. How to do this? Focussing on the individual addict was only a small part of the smoking story. What really made the difference was public education, social marketing, advertising bans, and eventually (and still to be achieved in many parts of the world) bans on smoking in public places.

So yes, let's find ways to make these conflicts of interest socially and professionally unacceptable-your ideas on how to do this would be welcome. But let's also have legislation in Europe, specifically a sunshine act requiring drug companies to declare who they pay and how much. And let's also see Europe follow Scotland, which puts the onus on doctors themselves to declare any ties with drug companies. As Andrew Jack says, getting the information from both sides would allow comparison between the two sets of data.

Cite this as: BMJ 2011;343:d6593

๑ BMJ Publishing Group Ltd 2011 